\title{
australasian journal of TECHNOLOGY EDUCATION
}

Editor: Professor P John Williams, University of Waikato, New Zealand

Consulting Editor : Professor Alister Jones, University of Waikato, New Zealand

Editorial board:

Prof Jacques Ginestié, Aix-Marseille Université, France

Prof Stephanie Atkinson, Sunderland University, England

Prof Frank Banks, The Open University, England

AProf Howard Middleton, Griffith University, Australia

Dr Gary O'Sullivan, Massey University, New Zealand

Prof John Ritz, Old Dominion University, USA

Prof Lung-Sheng Steven Lee, National Taiwan Normal University

Prof Marc de Vries, Delft University of Technology, Netherlands

Prof Malcolm Welch, Queens University, Canada

The Australasian Journal of TechnologyEducation is a peer refereed journal, and provides a forum for scholarly discussion on topics relating to technology education. Submissions are welcomed relating to the primary, secondary and higher education sectors, initial teacher education and continuous professional development, and general research about Technology Education. Contributions to the on-going research debate are encouraged from any country. The expectation is that the Journal will publish articles at the leading edge of development of the subject area.

The Journal seeks to publish

- reports of research,

- articles based on action research by practitioners,

- literature reviews, and

- book reviews.

Publisher: The Technology, Environmental, Mathematics and Science (TEMS) Education Research Centre, which is part of the Faculty of Education, The University of Waikato, publishes the journal.

Contact details: The Editor, AJTE, pj.williams@waikato.ac.nz

Cover Design: Roger Joyce

This journal provides immediate open access to its content on the principle that making research freely available to the public supports a greater global exchange of knowledge.

ISSN: 2382-2007 


\title{
australasian journal of TECHNOLOGY EDUCATION
}

\section{Contributions to Technology Education through Funds of Knowledge}

\author{
Wendy Fox-Turnbull
}

\begin{abstract}
The value and place of cultural knowledge, particularly that of minority groups, is frequently overlooked in school settings. However, when teachers are aware of students' backgrounds, and cultural practices, the likelihood of students making use of this knowledge increases. This article reports on a study that explored the contribution of students' Funds of Knowledge in undertaking technological activity. It explores the Funds of Knowledge deployed in technological practice and the role these played when students collaboratively developed their technological outcomes.
\end{abstract}

Set in a primary school with six and ten year old students, this study revealed that students deployed home and community knowledge when developing technological outcomes. The article introduces two sub-categories of Funds of Knowledge and compares the use of Funds of Knowledge between the two year levels and across a unit of work.

This study highlights the use of Funds of Knowledge in technology education and examines aspects within Funds of Knowledge that are applicable to it.

Key Words: technology education, Funds of Knowledge, collaborative learning, participatory enculturation, passive observation, primary technology.

\section{Introduction}

This article reports on a study that explores the nature of learning in the technology classroom using a collaborative approach; more specifically, it explores the role students' Funds of Knowledge play in contributing to learning in technology education in the primary classroom. The paper outlines the scope of the study and the data gathering processes. It then reviews relevant literature, particularly on classroom conversation and Funds of Knowledge, a term used by Gonzalez, Moll, and Amanti (2005) to describe knowledge and skills gained through community and family enculturation which students bring to their learning in the classroom. The paper introduces two methods that participants used to gain knowledge and skills from relevant culture and community: partipatory enculturation and passive observation.

\section{The Study}

The study took place in a New Zealand primary school and focused on six children in each of Years 2 and 6 (six to seven and ten to eleven year olds respectively). Over the period of a year, two technology units were taught in each class. At the conclusion of the first unit (Round One), six participant children were selected to be full participants in Round Two of the study during the implementation of the second unit. The study was undertaken by a participant researcher. 
The aim of this study was to gain an enhanced understanding of the learning that influenced students when developing technological solutions with the purpose of answering the research question: How do children's prior and ongoing experiences influence their learning and action when developing technological solutions?

Three methods of gathering data were employed in Round Two. The first was in-depth and semi-structured recorded interviews between the children or the classroom teachers and the researcher at intervals during the project. The second was audio recordings of the students as they worked in groups of three; recordings were transcribed and augmented with researcher observations. Student work samples were the third type of data, allowing triangulation of data. The last round of semi-structured interviews with the students used Stimulated Recall with students' auto-photographs of significant aspects their learning, as they worked through their technological practice. The technology task the students undertook was to design and develop props for use in the school production based on the whole school technology theme - the Olympic Games. In Year 2, this consisted of acting a traditional tale from Taiwan, and in Year 6 , it was the Olympic Games era of 1896-1936.

After transcription, recorded conversations were analysed and coded. Initial data suggested four distinct stages to the unit: Stage 1-The Character and Function of props; Stage 2 - Planning of Technological Outcomes (Props); Stage 3 - Creating a mock-up; and Stage 4 - Construction of the Props. Further analysis lead to an understanding of the sources of knowledge students deployed during their technological practice.

\section{Literature Review}

There are two aspects of literature relevant to this study. The first is the nature of conversation that advances thinking in an educational context; the second, community and cultural knowledge drawn on by students to assist their learning.

Learning and the development of new knowledge involves a process of deep collaboration and inquiry. Innovative solutions are more likely to arise when people in groups draw on evidence and on outside explicit knowledge and combine it with tacit knowledge in response to authentic problems (Nonaka \& Takeuchi, 1995). When people work together in problem solving situations they do much more than just talk together. They 'inter-think' by combining shared understanding, combining their intellects in creative ways, often reaching outcomes that are well beyond the capability of each individual. Problem solving situations involve a dynamic engagement of ideas with dialogue as the principal means used in establishing a shared understanding, testing solutions, and reaching agreement or compromise. Dialogue and thinking together are an important part of life and one that has long been ignored or actively discouraged in schools (Mercer \& Littleton, 2007). Structured conversations based on various forms of evidence can result in a real change of learning (Earl \& Timperley, 2008); however, having the conversations and the evidence is not enough. In such conversations, participants are required to reveal what they believe and why. Community and cultural environments and knowledge impact on the contributions they are able to make (Earl \& Timperley, 2008).

Gonzalez et al. (2005) call explicit outside cultural knowledge contributions 'Funds of Knowledge' (FOK). FOK are information, knowledge and skills students bring to learning from their culture, home, and community. Knowledge from experiences and activities undertaken at home or within their wider community and culture of the students are brought into the classroom to contribute to their engagement in and understanding of the lessons being taught (González et al., 2005). The term FOK was first coined by Gonzalez et al. in 2005. Lopez (2010) suggests that it is the responsibility of each teacher to "attempt to learn something special about each child they teach" (p. 2). Generating an understanding of students and their families' FOK is one way teachers can do this. 
The theory of Funds of Knowledge draws on the perspective that learning does not just happen but is a social process bound within a wider social context. People have wide knowledge, given to them through their life experiences. The knowledge that students come to school with can enhance their learning and facilitate useful interactions between knowledge found inside and outside the classroom. The more teachers know about the home and cultural activities and experiences of their students, the better able they will be to maximise learning opportunities and to make the most of knowledge and skills already accessible to some students (González et al., 2005). Lopez (2010). Fleer and Quinones (2009) also suggest that teachers can make more of the learning in their classrooms if they understand that students bring with them knowledge from their families, culture and background and that teachers should appreciate and can use this knowledge through purposeful classroom engagement. "One can create conditions for fruitful interactions between knowledge found inside and outside the classroom" (González et al., 2005, p. 20).

\section{Findings and Discussion}

The data from this study clearly demonstrated that students used their Funds of Knowledge to contribute to their learning in technology. The study found that FOK were gained through two means or methods: participatory enculturation and passive observation.

\section{Participatory enculturation}

Participatory enculturation involved being enculturated into an activity through engagement resulting in transferable knowledge. This engagement included active participation, where the child is involved in the activity, and peripheral participation where the child was on the periphery of the activity but was able to engage in it through questions and conversation. Gaining knowledge through participatory enculturation provided students with opportunities to know information their peers did not and be involved in practices unique to their family and culture. Knowledge gained from these experiences can therefore provide them status or mana (high status for Māori) within their peer group, and occurred through five means: family activity, afterschool activities, parents' occupation and interests, artefacts used at home, and family social and cooperative practices. In the sections below, each of these are discussed and illustrated in turn.

\section{Family activities}

Evidence of participatory enculturation through engagement in a family activity occurred very early in the props unit. As a part of the project, the students were given a disposable camera so that they could record their process of developing a prop. The students' first task was to ask a friend to take their photograph so that the first photograph in each camera was that of its owner. Moke was concerned that her camera was broken as this was her first experience with a nondigital camera; however, Duncan was able to reassure her as he had experienced how the photos are released. Wendy was the researcher $(\mathrm{R})$.

Moke: Wendy, my camera is broken.

R: What makes you say that Moke?

Moke: I cannot see the photograph inside the camera.

Duncan: Oh, it's okay. You just take them to The Warehouse and they hit them with a hammer and the photos jump out.

R: $\quad$ How do you know that Duncan?

Duncan: My Dad had one and we went to The Warehouse and that's what they did. 
This conversation illustrates that knowledge gained through participatory enculturation gave Duncan the confidence and status to reassure his classmate that her camera was not broken. It demonstrates that use and knowledge of technological devices gained from home and community assist students' confidence in their use.

After school activities

Students also brought learning from afterschool activities to assist them in understanding the character and function of props. Afterschool activities are defined as activities that students do independently of their family; typically going to external teachers for lessons or tutoring, playing sport or undertaking hobbies by themselves. When researching props, much of the information the students came across was from the United States of America. This is illustrated in the example below. Alan explained to the researcher how he knew the symbol " stood for inches. He cited the reason for knowing about this symbol (not taught in New Zealand schools), through his active participation in War Gaming on the computer. He also indicated that the knowledge may have come from his father.

R: $\quad 13$ and a half something. What does that mean?

Alan: Inches.

R: $\quad$ How do you know that, Alan?

Alan: It's like probably, I just know that from my father.

R: $\quad$ But, how did you know there's, you said inches. I can't see inches anywhere on that.

Alan: It's those two things. That's what inches is.

R: $\quad$ How do you know that?

Alan: Umm, because I do war gaming and that's what they use for inches,

The extract above illustrates how drawing on the information gained through participation assisted in understanding and interpreting information relating to research in another area. It is a requirement in technology to interpret designs of others. This extract demonstrates Alan's ability to interpret a symbol of measurement not used in his school environment but one that he uses in his home environment.

Parents' occupation and interests

The significance of the role of parents' occupations in what the students bring to their learning and that students use these FOK to position themselves as an expert and to gain mana from their peers became evident in the data. This was illustrated by three Year 6 children in the microphone group, as they discussed suitable materials for their microphone. Alan mentioned his Dad was a racing car designer and had a workshop at home. Dougal chipped into the conversation in a competitive manner explaining that his Dad has much more than blocks of wood because he worked in the construction industry. They had decided that the head of the microphone could be made from wood.

Dougal: My Dad owns a whole yard of everything. He's got lots of things, yeah. He's a drain layer. He's an excavation worker. He's a construction builder. He has a yard, a whole yard.

The conversation again illustrates how students used their FOK to position themselves as an expert through understanding that potential construction material is a significant aspect to planning technological outcomes. 
Artefacts used at home

The students also deployed knowledge gained through interaction with artefacts in the home environment. This was illustrated when Minnie and Dougal were problem solving how to hold the head of the microphone at the correct angle before attaching it to the stand. Dougal's photograph in Figure 1.1 shows Minnie holding the mocked-up version of this. The researcher approached them and asked what they are working on. When trying to explain to the researcher what they were doing Dougal used as an example from his home computer a docking station as illustrated in Figure 1.2. However, he refers to this as a 'whaling' station by mistake.

R: $\quad$ How are you going to attach, so what is this going to be?

Dougal: $\quad$ The base

Minnie: It's the base [together]

R: I know it's the base and it's to make it stand up, but what does it actually do?

Dougal: It's going to be like a whaling [docking] station at the back and um it's like, it's going to have like glue around it to stand by itself...

Microphone head

Connector between base

and stand- docking

Figure 1: Dougal's auto-photograph or mimnie nolding his micropnone head and docking station (holder)
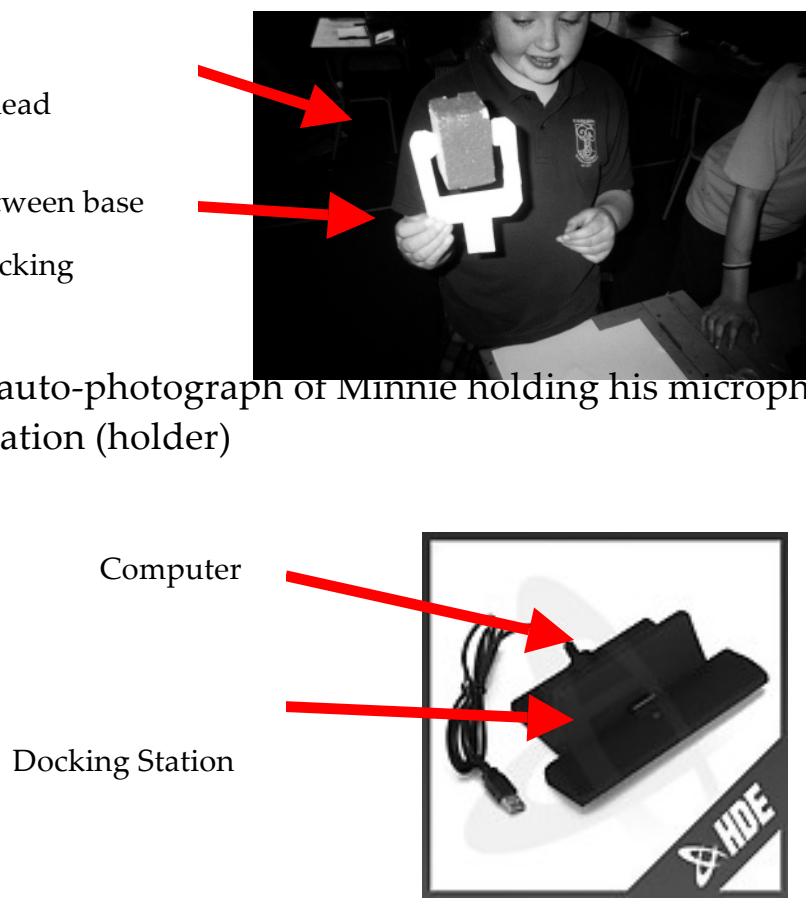

Figure 2: A computer docking station. Retrieved from http://shop.ebay.com.au/items

This extract and associated illustrations demonstrate how students made use of artefacts they knew, understood and used at home and in their community to make sense of learning undertaken at school. In this case, Dougal deployed an idea of one thing slotting into a specific place designed to hold it, to assist his design concepts and his explanation of his and Minnie's design. 
Family social and cooperative practices

Funds of Knowledge deployed by students were not only artefact and process knowledge and skills directly linked to home and community culture; they also deployed their community and family social skills and knowledge. This is relevant to planning design ideas in technology education because students are frequently required to design technological outcomes cooperatively and collaboratively. The next extract is a case in point, as these three Year 2 students had to agree on one final design. Rex deployed social FOK as he worked with Issy and Debby on the plan of their fish. Issy and Debby were having trouble deciding on the colours of their flying fish, and who decided what. Rex attempted peace-making by deploying a strategy his father used at home.

Debbie: I like the blue one.

Issy: I like the green one.

Rex: $\quad$ You can have the blue wings, the one there. The one of yours but just the wings. What one do you like?

Issy: $\quad$ I want the body.....

Debbie: But that one, yeah, have the body but not the face and I'll have the face and the.......

Issy: $\quad$ But I'm drawing the face. I'm drawing the face.

Re: $\quad$ No, that one. That one, eh.

Debbie: No.

Rex: $\quad$ That one.

Issy: Yeah.

Debbie: No.

Issy: $\quad$ Yes. We like it so there's cause...

Rex: What I used to do is if you there was two and there was one, so I did this, because my Dad always says, 'which one' and then the other two wanted two and then if there's one person who likes it, then we, we don't like it though.

Issy: [very softly] you just have to do it.

Students gain knowledge from their home and community through participatory enculturation. Learning through participatory enculturation involves the students in interaction with the context of learning. This can involve dialogue with participants, active engagement with materials, activities and artefacts, and practices that are an integral part of living in a community. The literature suggests that learning through active engagement is effective. Turnbull (2002) found that learning embedded in an authentic context proved more effective than learning in contextual isolation. Hennessy (1993, p. 15) suggests "learning is most successful when embedded in authentic and meaningful activity, making deliberate use of physical and social context" (p. 15). Rogoff's (1990) theory on cognitive apprenticeship methods of learning suggest that the enculturation of students to authentic practices through activity and social interaction facilitates effective learning. Mercer and Hodgkinson (2008) suggest that communication can be either interactive, verbal participation of both parties or noninteractive verbal participation of the teacher only. Conversation in participatory enculturation would be of the interactive nature.

This study showed that students gained knowledge through participatory enculturation in a number of ways, including engagement with parents' work and recreational activities. González 
et al. (2005) state that by drawing on household knowledge, the students' experiences are legitimated, thus authenticating the nature of classroom activity.

\section{Passive observation}

This second type of FOK identified refers to learned knowledge obtained through passive observation where the students were non-participatory observers; for example, through watching movies, television or reading books. In this method of gaining cultural knowledge and skills, the students did not interact directly with the knowledge source. The data suggests that students used knowledge gained in a passive observatory role and applied it to the learning that took place in their classroom, which illustrated that those students were able to transfer knowledge gained through passive means to inform their technological practice.

The students were also able to locate technology in historical and cultural contexts through passive observation. There were two aspects of historical location identified in the data. The first illustrated below, was that the students were able to understand that props assisted in the historical location of a play or setting. The students were given a range of photographs of play props. As Minnie talks to the researcher she recognises a cart. She knows they are from the past as she had heard about them in the song Little House on the Prairie - set in pioneer times in the mid-west of the United States of America.

The second was that students understood the function and form of an artefact in a historical setting. This is illustrated in the next extract. The students' main task was to develop props for the Olympic Games from 1896 to 1936. Alan and Dougal were able to recognise microphones from this era as they had seen them on television and the movies.

R: $\quad$ So how did you know that microphones looked like this?

Alan: $\quad$ Because umm, I saw a thing on TV.

Dougal: Yeah, like on movies and stuff.

This extract demonstrates that the knowledge the two boys had about microphones from the past came from watching television and movies, both activities commonly associated with their culture. This demonstrates that in technology education the students used prior observation to assist their personal construct of an object from a different era.

Students also gained an understanding of the purpose and role of props through passive observation. In Year 2, students listened to Julian, the props manager from the local theatre, who explained the purpose and function of props. He illustrated his talk with a range of props his company have used in the past. He discussed how each was used in situ. In the first extract, Issy is reminded of a show she saw in the previous school holidays. As an audience member she observed one particular prop used in a variety of ways.

Issy: I saw a show about a magic truck in the holidays and it changed [voice trails off]

Julian: Ohh, Auntie McDuff's Magical Trunk [name of the performance]. That was the show that we did in the last school holidays. Yeah, so what they did was they had this big box and they opened up bits of the box and when they opened up the front bit of the box, they put umm, a, a, they used a blackboard and they put a little drawing of some wheels at the bottom of the box and then that prop became a train or a car and then they'd close another bit and they'd open another bit and they'd put umm, a flag on it and it would become a boat. So sometimes...

Issy: ..and a $\operatorname{dog} \ldots$

Julian: and it became a dog at the end. Yeah. So sometimes you can use a prop a 
lot, lots and lots of different ways.

This extract illustrated that Issy used the knowledge she had gained from attending the theatre to assist her understanding of the definition of a technological outcome. Her input into the conversation indicated that she may have understood that the truck, as a prop, had multiple purposes.

The students deployed knowledge from passive observation to assist them in the construction of their designs. This occurred when students were problem solving possible solutions to design issues thus facilitating the construction of their designs. They deployed information learned through the watching of movies and television.

The data suggests that, in technology education, learning obtained through passive means is later deployed through active authentic means. These findings are somewhat surprising when taken in light of much of the research on effective learning. At the time of actual learning for these students, the context was not embedded in authentic meaningful activity; however, we can see that students deployed knowledge gained through these means to inform their practice, thus authenticating its deployment rather than the actual learning. Mercer and Littleton (2007) and Shields and Edwards (2005) argue that teachers need to engage in quality dialogue with students and parents to help them make sense both cognitively and experientially of the world in which they live and work. By doing this, teachers may be able to facilitate deployment of knowledge and skills learning through passive observation. González et al. (2005) suggest that teachers need to know and understand the communities and cultural practices of their students. Having an understanding of the activities their students are not only actively but also passively engaged in, will assist teachers in maximising learning opportunities in the classroom by actively making explicit connections to these practices and facilitating the deployment of the knowledge gained. This could occur through a range of methods: anecdotal conversations with students before and after school about their interests and hobbies; a formal survey of students, or the undertaking of a 'talents' unit early in the year in which students demonstrate their outside interests and talents to other class members. Clear articulation from the teacher to the students about the purpose of this information gathering, whatever form it takes, may enhance student participation in all the ideas above.

\section{Conclusion}

The study has identified two major methods for gaining FOK: participatory enculturation and passive observation. The study showed that learning through participatory enculturation occurred in a number of contexts: parental occupation, family activity, students' after school activity, artefacts used at home, and through social behaviours and guidelines implemented at home. The study also found that learning through passive observation played a role in students' learning in technology in that they were able to deploy this knowledge to assist their own and other's technological practice. Funds of Knowledge had considerable impact on learning as they assisted students' understanding of the historical and cultural location of artefacts and of practices of significant adults in work, recreational and in social settings.

This study attempted to answer research questions regarding student acquisition and deployment of knowledge and skill in technology education. The findings are significant because they indicate that students bring knowledge gained at home and in their community to technology education. This knowledge is then deployed to assist students' understanding and contributions when developing technological outcomes in a collaborative manner and developing technological literacy.

\section{Affiliation}

Wendy Fox-Turnbull

University of Canterbury 
PB 4800 Ilam

Christchurch, 8041, New Zealand

wendy.fox-turnbull@canterbury.ac.nz

\section{References}

Earl, L. M., \& Timperley, H. (Eds.). (2008). Professional learning conversations: Challenges in using evidence for improvement (Vol. 1). Nottingham, England: Springer.

Fleer, M., \& Quinones, G. (2009). Assessment of children's technological funds of knowledge as embedded community practices. In A. Jones \& M. J. DeVries (Eds.), International Handbook of Research and Development in Technology Education. Rotterdam, The Netherlands: Sense.

González, N., Moll, L. C., \& Amanti, C. (Eds.). (2005). Funds of knowledge. New York, NY: Routledge.

Hennessy, S. (1993). Situated cognition and cognition apprenticeship: Implications for classroom learning. Studies in Science Education, 22, 1-41.

Lopez, J. K. (2010). Funds of knowlege. Learn NC Retrieved from www.learnnc.org

Mercer, N., \& Hodgkinson, S. (Eds.). (2008). Exploring talk in school. London, England: Sage.

Mercer, N., \& Littleton, K. (2007). Dialogue and the development of children's thinking: A sociocultural approach. Oxon, England: Routledge.

Nonaka, I., \& Takeuchi, N. (1995). The knowledge creating company: How Japanese companies create the dynamics of innovation. Oxford, England: Oxford.

Rogoff, B. (1990). Apprenticeship in thinking: Cognitive development in social context. New York, NY: Oxford.

Shields, C., \& Edwards, M. (2005). Dialogue is not just talk: A new ground for educational leadership. New York, NY: Peter Lang.

Turnbull, W. (2002). The place of authenticity in technology in the New Zealand curriculum. International Journal of Technology and Design Education, 12, 23-40. 